THE JOURNAL OF INFECTIOUS DISEASES • VOL. 156, NO. 1 • JULY 1987

(C) 1987 by The University of Chicago. All rights reserved. $0022-1899 / 87 / 5601-0011 \$ 01.00$

\title{
Health Problems After Travel to Developing Countries
}

\author{
Robert Steffen, Martin Rickenbach, Urs Wilhelm, \\ Andrée Helminger, and Meinrad Schär
}

\author{
From the Vaccination Center, Institute for Social and \\ Preventive Medicine of the Zurich University, \\ Zurich, Switzerland
}

\begin{abstract}
Travelers to developing countries participated in a follow-up study of the health risks associated with short (less than three months) visits to these nations. Travelers to the Greek or Canary Islands served as a control cohort. Participants completed a questionnaire to elicit information regarding pretravel vaccinations, malaria prophylaxis, and health problems during and after their journey. Relevant infections were confirmed by the respondent's personal physician. The questionnaire was completed by 10,524 travelers; the answer rate was $73.8 \%$. After a visit to developing countries, $15 \%$ of the travelers reported health problems, $8 \%$ consulted a doctor, and $3 \%$ were unable to work for an average of 15 days. The incidence of infection per month abroad was as follows: giardiasis, 7/1,000; amebiasis, 4/1,000; hepatitis, 4/1,000; gonorrhea, 3/1,000; and malaria, helminthiases, or syphilis, $<1 / 1,000$. There were no cases of typhoid fever or cholera.
\end{abstract}

Recommendations for disease prophylaxis before travel to developing countries should be based on well-founded information about potential health risks. Some general surveys of health problems incurred during a stay abroad exist [1-3], but these studies did not examine infections with longer incubation periods. Surveys on specific diseases, such as malaria [4], hepatitis [5-9], typhoid fever [10, 11], other salmonelloses and shigelloses [12], cholera [13, 14], or travelers' diarrhea [15] may have missed cases or may have been partly biased by the retrospective approach [16]. The complete lack of data on travelers with chronic diarrhea after a stay in developing countries has recently been criticized [17]. Reports from clinics in tropical medicine only describe select and nonrepresentative populations.

Therefore, a follow-up study was set up to analyze incidence and importance of health risks, notably including diseases apparent only after a prolonged incubation period. Because $>80 \%$ of the tourists traveling to developing countries are vaca-

\footnotetext{
Received for publication 7 November 1986, and in revised form 13 February 1987.

This study was supported by funds from the Institute for Social and Preventive Medicine.

We thank the management and cabin crews of Balair; the Zurich airport authorities; the various travel agencies; Drs. Nils Billo, Hans Lobel, Suzanne Laussacq, Bertino Somaini, and Robert Tauxe for their valuable advice; Elisabeth Vollenweider for secretarial assistance; and Beth Urech-Rankin for linguistic assistance.

Please address requests for reprints to Dr. Robert Steffen, Vaccination Center ISPM, Sumatrastrasse 30, CH-8006 Zurich, Switzerland.
}

tioners, we concentrated on short-term visitors. Switzerland was suitable for such a project because $8 \%$ of its population visits developing countries each year [18]. Per capita, no other population spends more on international travel [19].

\section{Subjects and Methods}

Between July 1981 and June 1984, travelers $\geqslant 12$ years of age were recruited and given a brief bilingual (German/French) questionnaire. This questionnaire was distributed either during or just before boarding 112 charter and 12 scheduled flights to developing countries and to persons traveling by car or rail to Asia or Africa. Similarly, during one year, a minimal risk cohort was recruited as a control group from passengers on 19 charter flights to Rhodes, Kos, or Crete (Greece) and the Canary Islands (Spain). Only name, home address, destination, and duration of stay abroad were recorded in this first questionnaire.

Within this sample (travelers and control cohort) all those residing outside German-speaking Switzerland were excluded to enable an easier follow-up. The remaining travelers who had indicated that they would stay abroad no longer than three months received a second, retrospective questionnaire that was sent out seven months after departure (4-6.75 months after return). This questionnaire examined personal data, vaccinations, malaria prophylaxis, health problems during and after the journey as listed in table 3, need for medical services, and length of sick leave. If they wished, the persons could tear off the serial number to remain anonymous. In the fur- 
ther evaluation, questionnaires with confusing answers were excluded (table 1, exclusion II). In all relevant illnesses (table 5), the doctors treating the patient were asked to complete a third questionnaire and to send the laboratory results to confirm or correct the diagnosis reported by the patient. Diagnosis was considered "definite" if a large laboratory had evaluated the serological specimens. The diagnosis of non-A, non-B hepatitis was based on negative serrological tests for hepatitis A or hepatitis B virus infection, but hepatitis delta virus, cytomegalovirus, and Epstein-Barr virus infections were not excluded in all cases at the time of the investigation. Similarly, malaria, giardiasis, and amebiasis were considered "definite" when diagnosed in a hospital or by a doctor trained in tropical medicine; gonorrhea was accepted as "definite" when diagnosed in a smear by any doctor. Diagnosis was considered "possible" if such criteria were not fulfilled. Patients with hepatitis A or gonorrhea with too long an incubation period [20] were excluded. Chronic diarrhea was defined as persisting illness with at least three unformed daily stools, which resulted in at least five medical consultations, hospitalization of at least five days, inability to work for at least $\mathbf{1 5}$ days, or no cure by the time of the investigation.

The following travel characteristics were differentiated. A beach vacation was limited to a stay in one hotel only; guided tours were accompanied by a guide with lodging in international hotels. In individual tours the travelers stayed in international hotels without a guide; in adventure tours they lived in tents or cheap boarding houses. The other terms for travel and for destinations have been previously described [15].

Statistical evaluation was done by $\mathrm{A}$. $\mathrm{H}$. at the Zurich University Calculation Center by using an IBM 3033 with the SPSS-X program package. The $\chi^{2}$ test with Yates' correction was used to compare rates. When indicated, standard deviations are documented. To identify high-risk groups, we performed a multiple logistic regression analysis.

\section{Results}

Recruitment of the population is demonstrated in table 1 . For those indicated in table 1 as exclusion I, in $98 \%$ of the instances the reason was residence outside German-speaking Switzerland. Exclusion II mainly resulted from travelers taking a second journey to developing countries. Three of the question-
Table 1. Travelers recruited for this study.

\begin{tabular}{lccc} 
& \multicolumn{3}{c}{ Destination } \\
\cline { 2 - 3 } & $\begin{array}{c}\text { Developing } \\
\text { country }\end{array}$ & $\begin{array}{c}\text { Greek/Canary } \\
\text { Islands }\end{array}$ & Total \\
\hline Questionnaire & & & \\
\hline First questionnaire & 31,608 & 4,416 & 36,024 \\
$\quad$ No. distributed & 24,242 & 3,701 & 27,943 \\
No. answered & 76.7 & 83.8 & 77.6 \\
Answer rate (\%) & 12,990 & 693 & 13,683 \\
Exclusion I & & & \\
Second questionnaire & 11,252 & 3,008 & 14,260 \\
$\quad$ No. distributed & 8,192 & 2,332 & 10,524 \\
No. answered & 72.8 & 77.6 & 73.8 \\
Answer rate (\%) & 306 & 36 & 342 \\
Exclusion II & & & 10,182 \\
$\quad$ Total no. of travelers & & & \\
$\quad$ evaluated & 7,886 & 2,296 & 10,182 \\
\hline
\end{tabular}

naires (including two from the control group) were returned unanswered because the addressee had died for reasons unrelated to his journey. Fifty-two respondents remained anonymous.

Table 2 shows the characteristics of the population and of the journey. The mean age of the travelers was $39.9 \pm 14.2$ (control group, $32.9 \pm 13.5$ ) years; the mean duration of stay was $2.8 \pm 1.6$ weeks (control group, $2.1 \pm 0.8$ weeks). Health problems were significantly more frequent in young adults, visitors to West Africa, people on adventure tours, and in those groups who lived with natives, who went to work abroad, or who stayed for a prolonged period of time. In contrast, older travelers, visitors to East Africa or to Sri Lanka/Maldives, and those on guided tours were ill less often. Unless otherwise noted, the multiple logistic regression analysis of any single illness or accident showed no correlation with age, sex, destination, or season of travel. Table 3 contains type and period of occurrence of the main symptoms. The consequences of illness and accidents are listed in table 4.

No cases of typhoid fever, cholera, poliomyelitis, tuberculosis, or tetanus were reported. The illnesses diagnosed by medical professionals are summarized in table 5 .

Diagnosis of malaria was difficult to certify because more than half of the patients had been treated abroad and often were not evaluated by examination of a blood smear. Eleven of the twelve definite or possible cases of malaria originated in Africa. Two of these patients belonged to the $2.7 \%$ of all travelers to endemic areas who refused all prophylactic medication; four admitted that they did not comply with 
Table 2. Proportion of travelers who reported health problems.

\begin{tabular}{|c|c|c|c|c|}
\hline \multirow[b]{2}{*}{ Characteristics } & \multicolumn{2}{|c|}{ Developing countries } & \multicolumn{2}{|c|}{ Greek/Canary Islands } \\
\hline & $\begin{array}{l}\text { No. of } \\
\text { travelers* }\end{array}$ & $\begin{array}{l}\text { No. of } \\
\text { health problems }(\%)\end{array}$ & $\begin{array}{l}\text { No. of } \\
\text { travelers* }\end{array}$ & $\begin{array}{l}\text { No. of } \\
\text { health problems }(\%)\end{array}$ \\
\hline \multicolumn{5}{|l|}{ Sex } \\
\hline Men & 4,155 & $620(14.9)$ & 1,027 & $71(6.9)$ \\
\hline Women & 3,712 & $548(15.7)$ & 1,265 & $107(8.5)$ \\
\hline \multicolumn{5}{|l|}{ Age-group } \\
\hline $0-19$ & 238 & $36(15.1)$ & 239 & $19(7.9)$ \\
\hline $20-29$ & 2,114 & $428(20.2)^{\S}$ & 949 & $81(8.5)$ \\
\hline $30-39$ & 1,848 & $294(15.9)$ & 403 & $38(9.4)$ \\
\hline $40-49$ & 1,469 & $194(13.2)$ & 375 & $27(7.2)$ \\
\hline $50-59$ & 1,352 & $160(11.8) \ddagger$ & 227 & $9(4.0)$ \\
\hline $60-69$ & 651 & $68(10.4)^{\ddagger}$ & 71 & $3(4.2)$ \\
\hline $70-87$ & 181 & $26(14.3)$ & 20 & $0(0.0)$ \\
\hline \multicolumn{5}{|l|}{ Destination } \\
\hline East Africa & 2,628 & $340(12.9) \ddagger$ & - & - \\
\hline West Africa & 1,473 & $304(20.6)^{8}$ & - & - \\
\hline Sri Lanka/Maldives & 2,085 & $270(12.9)^{\dagger}$ & - & - \\
\hline Far East (east of Burma) & 531 & $72(13.6)$ & - & - \\
\hline Asia, various regions & 328 & $58(17.7)$ & - & - \\
\hline South America & 717 & $134(18.7)$ & - & - \\
\hline Greek Islands & - & - & 1,426 & $98(6.9)$ \\
\hline Canary Islands & - & + & 839 & $78(9.3)$ \\
\hline Various/other regions & 124 & $27(21.8)$ & 31 & $2(6.5)$ \\
\hline \multicolumn{5}{|c|}{ Travel characteristics (several answers possible) } \\
\hline Beach vacation & 5,156 & $757(14.7)$ & 2,089 & $160(7.7)$ \\
\hline Guided tours & 3,365 & $458(13.6)^{\dagger}$ & 154 & $17(11.0)$ \\
\hline Individual tours & 1,169 & $203(17.4)$ & 105 & $9(8.6)$ \\
\hline Adventure tours & 1,171 & $218(18.6)^{\dagger}$ & 139 & $14(10.1)$ \\
\hline Lived with locals & 736 & $139(18.9)^{\dagger}$ & 108 & $14(13.0)$ \\
\hline \multicolumn{5}{|l|}{ Lived with white } \\
\hline (control, Swiss) residents & 403 & $73(18.1)$ & 76 & $5(6.6)$ \\
\hline \multicolumn{5}{|l|}{ Reason for journey } \\
\hline Vacation & 7,317 & $1,098(15.0)$ & 2,276 & $176(7.7)$ \\
\hline Work, business & 97 & $20(20.6)$ & 4 & $1(25.0)$ \\
\hline Visit, various & 458 & $90(19.7) \dagger$ & 9 & $1(11.1)$ \\
\hline \multicolumn{5}{|l|}{ Duration of stay abroad } \\
\hline Up to one month & 7,348 & $1,070(14.6)$ & 2,275 & $175(7.7)$ \\
\hline Over one month & 533 & $139(26.1)^{8}$ & 21 & $3(14.3)$ \\
\hline Total & 7,886 & $1,209(15.3)$ & 2,296 & $178(7.8)$ \\
\hline
\end{tabular}

NOTE. The marginal distribution of the "health problems" variable served as a reference in the statistical analysis.

* Numbers do not add up to total, as some respondents did not answer all questions.

$\dagger P<.01$.

$\mp P<.001$.

$\S P<.0001$.

the prophylactic regimen. In three patients who had received single-agent prophylaxis but had acquired malaria in Kenya, parasite resistance to chloroquine, pyrimethamine, or Fansidar ${ }^{\circledR}$ was noted. In the remaining three patients, no explanation for their possible malaria could be found. Concordant with the Swiss doctrine, $75 \%$ of the visitors to Southeast Asia and South America took Fansidar prophylactically, but only one patient had malaria that originated in the Far East; this patient did not comply with the prophylactic regimen. Four definite cases were due to Plasmodium falciparum; the remaining one (the one from Asia) was due to Plasmodium vivax.

In hepatitis A and non-A, non-B hepatitis, no subpopulation with specific travel characteristics had a significantly increased or diminished incidence, including those travelers who took a brief beach vacation. The mean duration of inability to work due 
Table 3. Subjective description of the health problems reported by 1,209 of 7,886 short-term visitors to developing countries.

\begin{tabular}{|c|c|c|c|c|c|}
\hline \multirow[b]{3}{*}{ Symptom* } & \multicolumn{4}{|c|}{ Illness in travelers to developing countries } & \multirow{3}{*}{$\begin{array}{l}\text { No. of illnesses in } \\
\text { travelers to Greek } \\
\text { Canary Islands (\%) }\end{array}$} \\
\hline & \multirow[b]{2}{*}{ No. of cases $(\%)$} & \multicolumn{3}{|c|}{ Proportion ill $(\%)$} & \\
\hline & & $\begin{array}{c}\text { Abroad } \\
\text { only }\end{array}$ & $\begin{array}{c}\text { Abroad } \\
\text { and home }\end{array}$ & $\begin{array}{c}\text { Upon return } \\
\text { only }\end{array}$ & \\
\hline Severe diarrhea & $674(8.5)$ & 58 & 30 & 12 & $77(3.4)$ \\
\hline Vomiting or abdominal cramps & $315(4.0)$ & 54 & 31 & 15 & $49(2.1)$ \\
\hline Common cold & $171(2.2)^{\dagger}$ & 41 & 40 & 19 & $23(1.0)$ \\
\hline High fever over several days & $152(1.9)^{\ddagger}$ & 39 & 37 & 24 & $18(0.8)$ \\
\hline Dermatosis & $97(1.2)$ & 31 & 36 & 33 & $26(1.1)$ \\
\hline Chills & $87(1.1)$ & 29 & 41 & 30 & $10(0.4)$ \\
\hline Discharge (vagina/urethra) & $49(0.6) \ddagger$ & 20 & 43 & 37 & $8(0.3)$ \\
\hline Severe constipation & $45(0.6)$ & 57 & 39 & 4 & $8(0.3)$ \\
\hline Accident & $38(0.5)$ & 25 & 62 & 13 & $14(0.6)$ \\
\hline Jaundice & $24(0.3)$ & 17 & 29 & 54 & $3(0.1)$ \\
\hline Genital ulcer & $9(0.1)$ & 25 & 12 & 63 & - \\
\hline Various & $217(2.8)$ & 29 & 40 & 31 & $26(1.1)$ \\
\hline Total with health problems & $1,209(15.3)$ & 47 & 32 & $21 \S$ & $178(7.8)$ \\
\hline
\end{tabular}

* Several answers per traveler were possible.

$\dagger$ Women were more affected $(P=.02)$.

$\ddagger$ More days of illness if stay exceeded four weeks $(P=.05)$.

$\$$ In first week, $10 \%$; in second to fourth week, $8 \%$; the rest occurred later.

to hepatitis was 33 days. No other disease accounted for so many sick-days.

Chronic diarrhea was found in $73(0.9 \%)$ travelers. The highest rate $(\mathbf{1 . 8 \%})$ was noted upon return from West Africa and after journeys through various regions of the Far East $(P=.002)$. One-third of the patients became symptomatic only after returning home-some after a delay exceeding one month. Chronic diarrhea ranked second in days of inability to work. Ten cases each were associated with amebi-

Table 4. Consequences of health problems.

\begin{tabular}{lcc} 
& \multicolumn{2}{c}{ Destination } \\
\cline { 2 - 3 } Consequences & Developing countries & Greek/Canary Islands \\
\hline Medical consultations, numbers of travelers & $659(8.4)$ & $61(2.7)$ \\
Doctor abroad & $210(2.7)^{*}$ & $31(1.3)$ \\
Family physician after return & $331(4.2)$ & $30(1.3)$ \\
Specialist in tropical medicine after return & $123(1.6)$ & - \\
Various specialists after return & $76(1.0)$ & $7(0.3)$ \\
Outpatient clinic after return & $42(0.5)$ & $3(0.1)$ \\
Mean no. of visits & $4.0 \pm 5.2$ (median, 3) & $1.2 \pm 2.4$ \\
Hospitalization & $43(0.5)^{\dagger}$ & $1(0.04)$ \\
1 day only & $9(0.1)$ & $1(0.04)$ \\
$2-7$ days & $12(0.2)$ & - \\
$>1$ week & $22(0.3)$ & - \\
Inability to work & $241(3.1)$ & $26(1.1)$ \\
Mean duration (days) in those with inability & $15.1 \pm 19.1$ (median, 7) & $6.3 \pm 4.7$ (median, 5) \\
Mean duration (days) in entire surveyed sample & 0.46 & 0.07 \\
Not restored to health at the time of investigation & $75(1.0)^{*}$ & $9(0.4)$ \\
\hline
\end{tabular}

NOTE. Unless otherwise specified, data are no. of travelers $(\%)$.

* Sought consultation mainly because of severe diarrhea, fever, or dermatosis.

$\dagger$ Hospitalized mainly because of diarrhea of undetected origin, amebiasis, or hepatitis.

$¥$ Health was not restored mainly because of parasitosis, diarrhea of undetected origin, or accident. 
Table 5. Relevant infections in 7,886 short-term visitors to developing countries.

\begin{tabular}{lcc}
\hline & \multicolumn{2}{c}{$\begin{array}{c}\text { Diagnosis of illness } \\
\text { in travelers to } \\
\text { developing countries }\end{array}$} \\
\cline { 2 - 3 } Illness & Definite & Possible \\
\hline Malaria & 5 & 7 \\
Hepatitis (all) & 23 & 4 \\
Hepatitis A & 8 & - \\
Hepatitis B & $2^{*}$ & - \\
Hepatitis, non-A, non-B & 9 & - \\
Hepatitis, unclassified & 4 & 4 \\
Giardiasis & 34 & 4 \\
Amebiasis & 22 & 8 \\
Helminthsiasis & 5 & 2 \\
Paratyphoid B & 1 & - \\
Salmonellosis, other & 5 & 1 \\
Shigellosis & 1 & - \\
Gonorrhea & $17^{\dagger}$ & $6 \dagger$ \\
Syphilis & 2 & - \\
\hline
\end{tabular}

NOTE. In the control group, travelers to the Greek/Canary Islands, there was only one "possible" case of illness diagnosed: hepatitis B (see text).

* Subject worked with native population.

$\dagger$ Mostly men had gonorrhea.

asis or giardiasis, and a few were associated with helminthiasis; however, the majority of cases were of undetected origin. Giardiasis, amebiasis, and helminthiasis occurred less frequently in vacationers than in those who worked or stayed with natives $(P=.004)$.

Accidents affected $38(0.5 \%)$ travelers; 32 of them sought medical attention, and 10 had to be hospitalized, half of them for more than a month. The mostsevere cases resulted from traffic accidents $(n=3)$ or assaults $(n=2)$, whereas the most-frequent ones resulted from lacerations received during water sports $(n=17)$.

In the control cohort, far less $(7.8 \%$ vs. $15.3 \%$, $P<.0001)$ serious health problems were reported. Travelers to the Greek or the Canary Islands also reported fewer relevant symptoms (tables 3 and 4). No cases of severe infection were confirmed (table 5). Although hepatitis B was proven in a patient, he may have been infected while still in Switzerland through contact with a drug abuser who had hepatitis B. Only six cases of chronic diarrhea were recorded; none persisted at the time of the investigation. Only dermatological problems (mainly sunburn) and accidents occurred slightly more frequently in the control group. No significant difference in any symptom was found between the travelers to the Greek and the Canary Islands.

\section{Discussion}

This study is representative for Swiss-German tourists vacationing in the most-popular developing countries and on the Greek and the Canary Islands. The high response rate to our questionnaire shows that the vast majority of travelers to developing countries are aware and concerned about possible medical problems. The difference in the mean age between the study and the control cohort is explained by the fact that younger people, mainly women, cannot afford the longer trip and prefer beach vacations. Possible biases must be considered - mainly difficulties in recall and lack of uniform standard of diagnosis. The study sample was not controlled with respect to prophylaxis, exposure, and treatment; therefore, the study realistically illustrated the variations in a tourist population.

Figure 1 summarizes the incidence rates of infections. A slight inexactness may arise from extrapolating from a 2.8-week to a one-month stay; e.g., in diarrhea the incidence decreases with time. With exceptions to be discussed below, the rates provided by former retrospective case-history studies are confirmed by this follow-up study. In general, age, destination, travel characteristics, and, above all, duration of stay abroad play a significant role. High-risk travelers, therefore, need more-detailed medical recommendations. A very high risk for any single serious health problem, which could have been prevented by drug or immunization prophylaxis, was not more prevalent in any one subgroup.

Malaria was imported from Africa at a rate of $97.6 / 100,000$; this rate includes only definite cases. The Centers for Disease Control (CDC; Atlanta, Ga) calculated an attack rate of $108.0 / 100,000$ in U.S. travelers to Kenya [21]. Imported malaria, however, illustrates only a part of the problem, as even in short-term travelers an important proportion of cases is treated abroad and is not reported. Increasing distribution of chloroquine-resistant $P$. falciparum and growing concern about adverse reactions due to Fansidar $[22,23]$ and amodiaquine $[24,25]$ are likely to lead to diminished protection of the travelers visiting endemic areas and to a further increase in the incidence of malaria. A more-detailed analysis of the risk of malaria with respect to different types of prophylaxis has just been published [26]. 


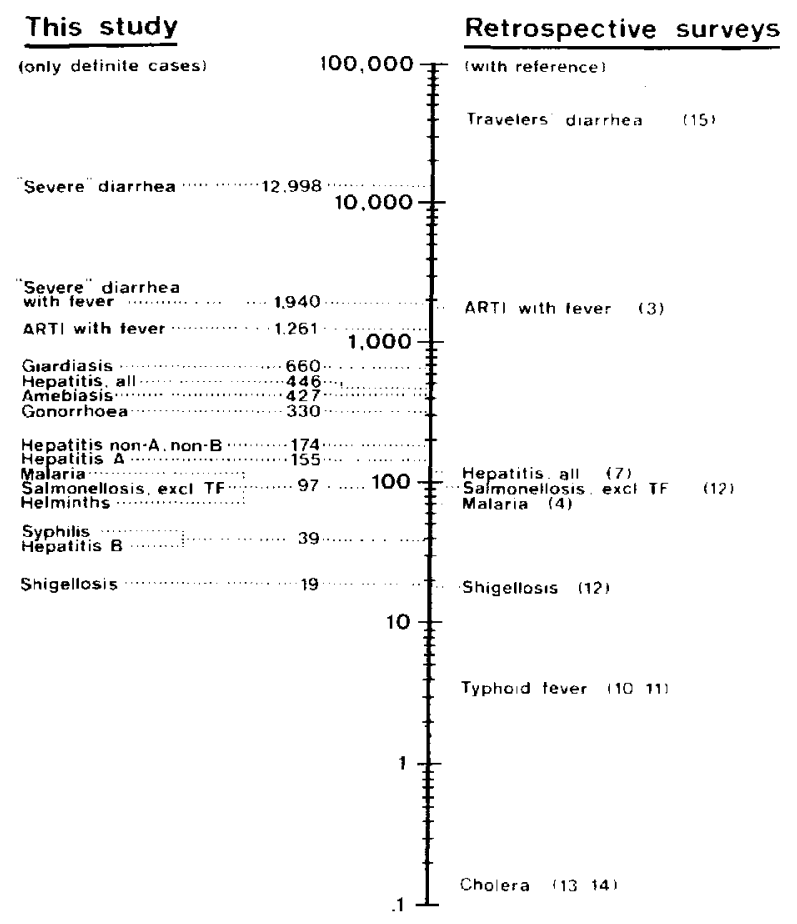

Figure 1. Incidence of infections per 100,000 travelers for a stay of one month in a developing country. The incidence rates per month were calculated by multiplying the rate for the mean duration of stay of 2.8 weeks by a factor of 1.53. $A R T I=$ acute respiratory tract infection, $T F=$ typhoid fever.

Hepatitis A, non-A, non-B hepatitis, or hepatitis $B$ affected 291.6 (hepatitis A only, 101.4) $/ 100,000$ visitors to developing countries in the 2.8-week stay. This is three times the rate observed in most retrospective surveys [5-7], which were usually performed before serological differentiation was possible, and is five times more than the rate observed in the preliminary CDC report [1], which, however, included travelers to Europe. As noted [5, 8], a considerable proportion of cases was missed in the older casehistory surveys. In contrast, a Swedish source has reported a higher rate of $600-1,000 / 100,000$ travelers exclusively for hepatitis A for a mean stay abroad of two weeks [9]. In our study, some cases of hepatitis A may have been counted as unclassified hepatitis, as antibody to hepatitis A virus was not yet regularly assessed in the early 1980s. The high proportion of non-A, non-B hepatitis (table 5) probably results from chance, as usually non- $A$, non-B hepatitis accounts for only $20 \%$ of all cases of imported hepatitis [7]. Although seven of those nine patients took Fansidar, the prolonged course of hep- atitis is not suggestive of a sulfonamide drug reaction [27].

Hepatitis occurred exclusively in travelers who had not received immunoglobulin. Such prophylaxis is given only to $5 \%$ of Swiss travelers (mainly adventurers) to developing countries (Steiger E, unpublished observation). With such protection, this highrisk group may therefore not appear as excessively exposed as in a former survey [5]. Travelers eating and drinking exclusively in tourist-class accommodations are at less risk [28], but our results indicate that the risk of hepatitis in this group is currently being underestimated [28]. Prophylactic immunoglobulin may be suggested for each traveler to a developing country. This prophylaxis would be expensive but may well have a benefit worth the additional cost [29], even if it protects only $85 \%$ from hepatitis A [30]. A claimed protection against non-A, non-B hepatitis [31] remains unconfirmed.

Although almost no Swiss traveler was effectively immunized against typhoid fever [32] and only a few were immunized against cholera, no infections were reported. This adds evidence to the fact that it is sufficient to recommend typhoid vaccination mainly for travelers "off the usual tourist itinerary" [28] and to those visiting India [32]. Cholera vaccination is certainly not to be advised to all visitors to Asia and Africa; however, some authors from both sides of the Atlantic still do so [33, 34], and this procedure is widely practiced, e.g., by British doctors attending a meeting in Egypt [35] and in profit-oriented vaccination centers. At the current New York price of $\$ 35.00$ for two injections, with an incidence of $1 / 500,000$ travelers and a case fatality rate of $1.6 \%$ [14], over a billion dollars would be spent to prevent one fatal case of cholera. This vaccination should be restricted to those visiting the few remaining countries continuing to request a certificate despite the 1973 World Health Assembly recommendations [36].

Only $8.5 \%$ of all travelers suffered from "severe" diarrhea. This is far less than in our former survey of travelers' diarrhea [15] because in this study we concentrated on chronic or incapacitating forms. One of the goals was to determine the rate of parasitic and bacterial intestinal infections in an unselected group consisting of mainly vacationers after their return home. The true infection rate is higher because it is known for giardiasis [37], amebiasis [38] (exceptionally in helminthiasis [39]), and salmonellosis that asymptomatic course and spontaneous eradication may occur, but this proportion is of 
smaller practical consequence. Diarrhea occurring after return home tended to last longer and to become chronic compared with cases occurring while abroad [15]. This may result from parasitoses that have incubation periods ranging from weeks to months [20].

Serious accidents rarely occurred - only $1 \%$ of the travelers had to be hospitalized. Nevertheless, travelers ought to be reminded to wear shoes while swimming over coral reefs and to carefully disinfect any laceration, however small it may be. These two measures alone would avoid a substantial proportion of the cases with subsequent inability to work. The slightly higher incidence of trauma in the control cohort may be associated with the lower average age - young people being more prone to sports and traffic accidents. No fatalities were recorded. Even in Peace Corps volunteers, who may be more exposed to danger than are vacationers, the rate was only $1 / 1,000$ persons-years [40].

\section{References}

1. Kendrick MA. Study of illness among Americans returning from international travel, July 11-August 24,1971 , preliminary data. J Infect Dis 1972;126:684-5

2. Gangarosa EJ, Kendrick MA, Lowenstein MS, Merson MH, Mosely JW. Global travel and travelers' health. Aviat Space Environ Med 1980;51:265-70

3. Steffen R, Van der Linde F, Meyer HE. Erkrankungrisiken bei 10500 Tropen- und 1300 Nordamerika-Touristen. Schweiz Med Wochenschr 1978;108:1485-95

4. Lobel HO, Campbell CC, Schwartz IK, Roberts JM. Recent trends in the importation of malaria caused by Plasmodium falciparum into the United States from Africa. J Infect Dis 1985;152:613-7

5. Steffen R, Regli P, Grob PJ. Wie gross ist das Risiko einer Reisehepatitis? Retrospektive Studie in der Region Zürich 1971-1976. Schweiz Med Wochenschr 1977;107:1300-7

6. Skinhøj P, Gluud C, Ramsoe K. Traveller's hepatitis. Origin and characteristics of cases in Copenhagen 1976-1978. Scand J Infect Dis 1981;13:1-4

7. Apothéloz M, Grob PJ, Steffen R, Schär M. Welchen Auslandreisenden ist en Impfschutz gegen Hepatitis zu empfehelen? Soz Praventivmed 1982;27:264-5

8. Hall SM, Mortimer PP, Vandervelde EM. Hepatitis A in the traveller. Lancet 1983;2:1198

9. Christenson B. Epidemiological aspects of acute viral hepatitis A in Swedish travelers to endemic areas. Scand J Infect Dis 1985;17:5-10

10. Steffen R. Typhoid vaccine, for whom? Lancet 1982;1:615-6

11. Taylor DN, Pollard RA, Blake PA. Typhoid in the United States and the risk to the international traveler. J Infect Dis 1983;148:599-602

12. Steffen R, Schär G, Mosimann J. Salmonella and Shigella infections in Switzerland, with special reference to typhoid vaccination for travellers. Scand J Infect Dis 1981;13:121-7
13. Snyder JD, Blake PA. Is cholera a problem for US travelers? JAMA 1982;247:2268-9

14. Morger H, Steffen R, Schär M. Epidemiology of cholera in travellers, and conclusions for vaccination recommendations. Br Med J 1983;286:184-6

15. Steffen R, Van der Linde F, Gyr K, Schär M. Epidemiology of diarrhea in travelers. JAMA 1983;249:1176-80

16. Kozicki M, Steffen R, Schär M. "Boil it, cook it, peel it or forget it". Does this rule prevent travellers' diarrhoea? Int J Epidemiol 1985;14:169-72

17. Consensus conference. Travelers' diarrhea. JAMA 1983;253: 2700-4

18. Bundesamt für Statistik. Reiseverkehr der Schweizer im Ausland 1984. Bern: Bundesamt für Statistik 1985

19. Weise HJ. Die Entwicklung des internationalen Tourismus und des nationalen Urlaubsverhaltens. Bundesgesundheitsblatt 1982;25:275-9

20. Benenson AS. Control of communicable diseases in man. 14th ed. Washington, DC: American Public Health Association, 1985:7, 157, 160,169, 383

21. Lobel HO, Campbell CC. Malaria prophylaxis and distribution of drug resistance. Clin Trop Med Commun Dis 1986;1:225-41

22. Centers for Disease Control. Revised recommendations for preventing malaria in travelers to areas with chloroquineresistant Plasmodium falciparum. MMWR 1985;34:185-95

23. Steffen R, Somaini B. Severe cutaneous adverse reactions to sulfadoxine-pyrimethamine in Switzerland. Lancet 1986;1:610

24. Hatton CSR, Peto TEA, Bunch C, Pasvol G, Russell SJ, Singer CRJ, Edwards G, Winstanley P. Frequency of severe neutropenia associated with amodiaquine prophylaxis against malaria. Lancet 1986;1:411-4

25. Neftel KA, Woodtly W, Schmid M, Frick PG, Fehr J. Amodiaquine induced agranulocytosis and liver damage. $\mathrm{Br} \mathrm{Med}$ J 1986;292:721-3

26. Lobel HO, Roberts J, Somaini B, Steffen R. Efficacy of malaria prophylaxis in American and Swiss travelers to Kenya. J Infect Dis 1987;156:1205-1209

27. Wejstal R, Lindberg J, Malmvall B-E, Norkrans G. Liver damage associated with Fansidar. Lancet 1986;1:854-5

28. Centers for Disease Control. Health information for international travel 1986. Atlanta: Centers for Disease Control, 1986:86, 110

29. Doubilet P, Weinstein MC, McNeil BJ. Use and misuse of the term "cost effective" in medicine. N Engl J Med 1986;314:253-6

30. Immunization Practices Advisory Committee. (ACIP). Recommendations for protection against viral hepatitis. MMWR 1985;34:313-24, 329-35

31. Joshi YK, Babu S, Sarin S, Tandon BN, Gandhi BM, Chaturvedi VC. Immunoprophylaxis of epidemic non-A non-B hepatitis. Indian J Med Res 1985;81:18-9

32. Wüthrich RP, Somaini B, Steffen R, Hirschel B. Typhusepidemiologie in der Schweiz 1980-1983. Geringe oder fehlende Wirksamkeit des lebendimpfstoffes rivotif bei tropenreisenden. Schweiz Med Wochenschr 1985;115:1714-20

33. Leach RD. Medical aspects of ocean yacht voyages. Travel and Traffic Medicine International 1984;2:31-4

34. Allard $R$. Problems in adequately immunizing international travellers. Can Med Assoc J 1983;128:40-1 
35. Mitchell ABS. Foreign travel and health: mutually exclusive? Practitioner 1985;229:827-30

36. World Health Organization, Vaccination certificate requirements and health advice for international travel. Geneva: WHO, 1985

37. Jokipii L, Jokipii AM. Giardiasis in travelers: a prospective study. J Infect Dis 1974;130:295-9

38. Nanda R, Baveja U, Anand BS. Entamoeba histolytica cyst passers: clinical features and outcome in untreated subjects. Lancet 1984;2:301-3
39. Croll NA, Anderson RM, Gyorkos TW, Ghadirian E. The population biology and control of Ascaris lumbricoides in a rural community in Iran. Tran R Soc Trop Med Hyg 1982;76:187-97

40. Hargarten SW, Baker SP. Fatalities in the Peace Corps. A retrospective study: 1962 through 1983. JAMA 1985; 254:1326-9 